\title{
Bilirubin encephalopathy due to Rh incompatibility
}

\author{
Encefalopatia bilirrubínica por incompatibilidade Rh \\ Taísa Roberta Ramos Nantes de Castilho ${ }^{1}$, Marcelli Salete Vargas ${ }^{1}$, Adriana Pinsuti ${ }^{1}$, \\ Marcos Augusto Rocha ${ }^{1}$, Jose Ricardo D’Bertagnon ${ }^{1}$
}

\section{ABSTRACT}

The authors present the case of a newborn of an Rh-factorsensitized mother, who received early hospital discharge while icteric only to be readmitted at an Emergency Service at five days of age with signs of kernicterus. Despite treatment given, the neonate progressed with a clinical picture of bilirubin encephalopathy. The lack of interaction between the obstetric and neonatal teams, premature hospital discharge, and lack of concern of neonatologists with jaundice in a full-term infant are highlighted as causes of a condition that should have disappeared if there had been adequate prevention.

Keywords: Kernicterus/etiologia; Jaundice, neonatal; Blood group incompatibility/complications; Case reports

\section{RESUMO}

Os autores apresentam o caso de um recém-nascido cuja mãe apresentava sensibilização ao fator $\mathrm{Rh}$, que teve alta precoce da maternidade, ictérico, e que voltou a um pronto-socorro para ser novamente internado, aos 5 dias de vida, com sinais de kernicterus. Apesar da terapêutica instituída, evoluiu com quadro de encefalopatia bilirrubínica. Merecem atenção a falta de interação entre as equipes obstétrica e neonatal, a alta precoce e a falta de preocupação dos neonatologistas com a icterícia em recém-nascido de termo como causas de uma afecção que deveria ter desaparecido por existir prevenção adequada.

Descritores: Kernicterus/etiologia; Icterícia neonatal; Incompatibilidade de grupos sanguíneos/complicações; Relatos de casos

\section{INTRODUCTION}

Acute bilirubin encephalopathy (BE), also called bilirubin-induced neurological dysfunction, is a clinical neurological syndrome resulting from exposure to bilirubin and its potential neurotoxicity, with an incidence that varies from 0.4 to $2.9 / 100000$ liveborns ${ }^{(1)}$. Its pathogenesis is multifactorial, involving time of exposure to levels of bilirubin and even individual characteristics of each newborn (NB). The term "kernicterus", which refers strictly to the description of pathology findings of indirect bilirubin impregnation of certain areas of the brain, is frequently used as a synonym of BE, although currently these are defined separately as $\mathrm{BE}$ and kernicterus, as per the description of the American Academy of Pediatrics ${ }^{(2)}$.

The pathogenesis of $\mathrm{BE}$ and of kernicterus is multifactorial and involves interaction between levels of indirect bilirubin, duration of exposure to high levels, albumin binding, levels of free bilirubin, passage through the brain blood barrier, and neuronal susceptibility to injury ${ }^{(3)}$.

Among the probable etiologies of $\mathrm{BE}$, hemolytic jaundice by Rh-isoimmunization stands out, and is one of the causes of greatest risk along with a deficiency in G6PD (glucose-6-phosphate dehydrogenase), followed by ABO-incompatibility ${ }^{(4)}$. Other causes include prematurity, hereditary spherocytosis, sepsis, hepatitis, cytomegalic inclusion diseases, nonspherocytic congenital anemia, non-hemolytic familial jaundice (Crigler-Najjar) and hemoglobinopathies ${ }^{(3)}$. Other associated conditions, such as asphyxia, infections, hypercarbia, and hyperosmolarity also increase risks. The blood level at which bilirubin is toxic for each NB is unpredictable, but $\mathrm{BE}$ is unlikely in healthy full-term infants and in the absence of hemolysis under $20 \mathrm{mg} / \mathrm{dL}$; there are various tables used for follow-up ${ }^{(4-7)}$.

Currently, in the United States, a rise in registered cases of $\mathrm{BE}$ has been seen as a consequence of various factors: increased number of children inadequately breastfed, short hospital stay (less than 48 hours), and the practice of scheduling the first visit to the pediatrician

Universidade de Santo Amaro - UNISA/ Hospital Geral do Grajaú/Organização Santa Catarina - São Paulo (SP), Brazil.

Corresponding author: Taisa Roberta Ramos Nantes de Castilho - Hospital Estadual do Grajaú - Rua Francisco Octávio Pacca, 180 - Parque das Nações - CEP 04822-030 - São Paulo (SP), Brasil Tel.: (11) 3544-9444- e-mail: ta_castilho@hotmail.com

Received on: Jan 18, 2011 - Accepted on: Apr 19, 2011

Conflicts of interest: none 
between one and two weeks after hospital discharge $\mathrm{e}^{(5-7)}$. The presentation of the following case has the objective of drawing attention to these aspects.

\section{CASE REPORT}

Male NB, 5 days-old, born in and coming from the city of Sao Paulo (SP), was taken to the Emergency Room of the Hospital Geral do Grajaú (HGG) presenting with fever and hypoactivity. According to information obtained from the mother's pregnancy card, the child, who was born at another hospital in the city of Sao Paulo, had the gestational age of 37 and 5/7 weeks, was delivered naturally, with a birth weight of 3260 grams, length of $49 \mathrm{~cm}$, recorded Apgar score 9/10, and blood type B Rh positive. The mother had experienced a high-risk pregnancy due to prior Rh-sensitization, with three gestations, two deliveries, and one miscarriage. She had eight prenatal visits, and presented with blood type $\mathrm{B} \mathrm{Rh}$ negative, positive for indirect Coombs test. Hypertensive, she took Aldomet ${ }^{\circledR}$ as antihypertensive medication, and had a urinary tract infection which was treated during the second trimester. She had negative serology for toxoplasmosis, cytomegalovirus, rubella, and HIV. The NB was discharged from the hospital on the second day of life, with jaundice, with no other complications, as per the mother's report.

During the first day at home, the infant showed decreased feeding, moaning, and nausea, associated with hyperthermia $\left(39^{\circ} \mathrm{C}\right)$. Upon examination at the ER of the HGG, the child presented with a regular to poor clinical condition, with moderate dehydration, jaundice grade $4 / 4$, risk zone 5, hypoactivity, and spasms in the limbs which subsided with the administration of sedatives. There were no abnormalities upon cardiac or pulmonary auscultation. The abdomen was flat, flaccid, with no masses or visceromegaly, the fontanel was normotensive, with miotic pupils, paroxysmal contractions in upper and lower limbs, besides hyperextension of the head. There were no references as to the infant's blood type or direct Coombs test; merely the mother's report that he was icteric on the day of hospital discharge.

Ancillary tests upon admission were: $\mathrm{Hb}: 9.2 \mathrm{~g} /$ dL; Ht: 26.9\%; leukocytes: 8700 (1 metamyelocyte, 10 band neutrophils, 65 segmented neutrophils, no eosinophils, 20 lymphocytes, 4 monocytes); platelets: 284000; sodium: $143 \mathrm{mg} \%$; potassium: $4.5 \mathrm{mg} \%$; total bilirubin: $35.97 \mathrm{mg} \%$; indirect bilirubin: $32.42 \mathrm{mg} \%$; direct bilirubin: $3.55 \mathrm{mg} \%$; creatinine: $0.3 \mathrm{mg} \%$; urea: $66 \mathrm{mg} \%$; C-reactive protein: $2.9 \mathrm{mg} \%$ (reference value $<6.0$ ); type 1 urine test with density: 1020 , ph: 6.5 , protein: $2+$, leukocytes: 191000 , erythrocytes: 50000, and absent yeasts. Samples were collected for cultures of the blood, urine, and CSF.
The patient was transferred to the Pediatric Intensive Care Unit (ICU), where he was submitted to vigorous hydration, $20 \%$ albumin transfusion $(1 \mathrm{~g} / \mathrm{kg})$, and exchange transfusion (ET), with $\mathrm{O}$ erythrocytes and $\mathrm{AB}$ plasma; there were no complications - the procedure lasted 2 hours and 20 minutes, and the infant maintained normal monitoring. The patient was placed under phototherapy (1 Bilitron ${ }^{\circledR}$ and Biliberço $\left.{ }^{\circledR}\right)$ and antibiotics were introduced with cephotaxime and oxacillin until the culture results were ready. During sedation to contain the spasms, the patient experienced apnea and orotracheal intubation was necessary. After the ET, results showed total bilirubin of $21.28 \mathrm{mg} \%$ (direct was $15.55 \mathrm{mg} \%$ ), $\mathrm{Hb} 7.1 \mathrm{~g} \%$ and $\mathrm{Ht} 20.1 \%$, and he received an erythrocyte transfusion. On the following day, phototherapy was maintained, and total bilirubin was 5.85 (direct at $4.19 \mathrm{mg} \%$ ), reticulocytes $2.0 \%$, albumin $2.6 \mathrm{mg} \%$. The final blood culture result was negative and the urine culture showed growth of Escherichia coli > $100000 \mathrm{UFC} / \mathrm{mL}$ (multi-sensitive). The cerebrospinal fluid chemistry and cytology tests were normal and the culture was negative, ruling out the diagnosis of meningitis. Urinary tract ultrasound was normal. On the $12^{\text {th }}$ day, the patient experienced cardiorespiratory arrest, which was reverted with cardiac massage and medication, followed by hemodynamic instability and need to use vasoactive drugs and ventilation therapy. The antibiotics were changed. During this stay in the ICU, the patient progressively improved and was weaned from mechanical ventilation; on the $27^{\text {th }}$ day he was transferred to the clinical ward, requiring inhaled oxygen and anticonvulsive medication. He then presented with hypoactivity and difficulty swallowing, and a nasogastric tube was maintained. A computed tomography scan showed no alterations.

In the inpatients unit, his clinical condition worsened in association with a new episode of apnea and oxygen saturation drop, followed by another cardiorespiratory arrest, which was reverted with bag and mask ventilation and drugs, and the patient was readmitted to the pediatric ICU. Difficulty in swallowing was noted, and a percutaneous endoscopic gastrostomy was performed to enable adequate nutrition. The patient was transferred back to the ward and discharged from the ICU. He remained in the clinical ward until hospital discharge, with anticonvulsive medications and clinical support. A brain MRI was performed, which, as per official report, showed no significant alterations (Figure 1). After the second transfer to the medicalward, he maintained a regular general clinical status, hypoactive, non-responsive to stimuli (verbal or visual), hypotonic, with dependence on intermittent inhaled oxygen and occasional bouts of apnea. The patient showed improvement of this condition, and was discharged from hospital. He is currently under 
outpatient clinic follow-up of this specialty, an auditory brainstem response (ABR) has been scheduled and the patient maintains the same neurological status.

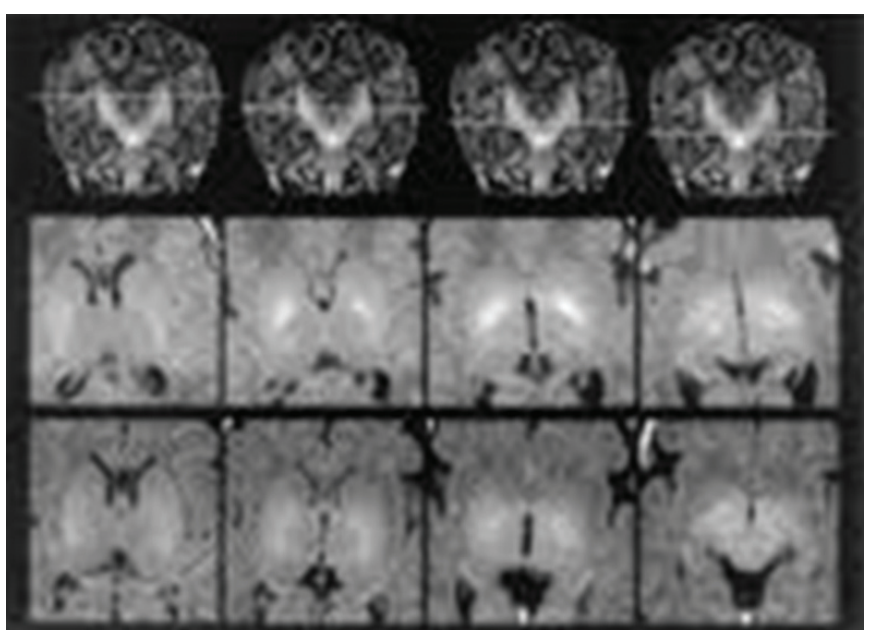

Figure 1. MRI of the patient showing no alterations suggesting kernicterus

\section{DISCUSSION}

Despite advances over the last decades in prevention of perinatal hemolytic disease by $\mathrm{Rh}$ isoimmunization, at triage and during treatment for hyperbilirubinemia this NB evolved with a probable $\mathrm{BE}$ due to $\mathrm{Rh}$ isoimmunization.

The clinical case presented confirms the need for adequate follow-up, from the prenatal to the postnatal period, as per the protocol established ${ }^{(8)}$ to avoid the progression and final outcomes seen in this case. The patient's mother, during a previous gestation, had given birth to a baby with severe jaundice that required similar treatment. For this reason, in this gestation she had high-risk prenatal care, when she presented with positive indirect Coombs testing, requiring appropriate support to check for fetal alterations. Despite medical care during the prenatal phase, the neonatal team was unprepared for adequate neonatal follow-up of the $\mathrm{NB}$, with no Rh or Coombs evaluation, which led to discharge of an icteric newborn on the $2^{\text {nd }}$ day of life.

The neurological manifestations of hyperbilirubinemia frequently appear between the $2^{\text {nd }}$ and $5^{\text {th }}$ days of life, when the serum bilirubin levels rise to more than $20 \mathrm{mg} / \mathrm{dL}$ in the full-term $\mathrm{NB}$, and include somnolence, hypotonia and opisthotonus - clinical findings present in this case ${ }^{(9)}$.

ThepathogenesisofBEismultifactorial,but,ifassociated with other disorders, increases the risk of neurological intoxication (such as asphyxia, infections, hypercarbia, and hyperosmolarity). In this case, a concomitant condition of urinary tract infection may have contributed towards worsening of the neurological picture, by increased bloodcerebrospinal fluid patency, hypoalbuminemia, and a greater risk of bilirubin neurotoxicity ${ }^{(4,7)}$.
The treatment established, including ET and phototherapy, also used a $20 \%$ infusion of albumin (1 $\mathrm{g} / \mathrm{kg}$ ) - one hour before the ET, in order to significantly reduce the levels of serum bilirubin after this procedure and during phototherapy ${ }^{(10)}$.

In the case described, no alterations were identified on the brain imaging tests that could suggest a diagnosis of BE. By means of the MRI, in most cases, there is a symmetrical bilateral hypersignal in the hippocampus, thalamus, subthalamus, and globus pallidus in $\mathrm{T} 1$ and $\mathrm{T} 2^{(11)}$. Alterations in the globus pallidus correspond to the preferential areas for non-conjugated bilirubin deposits ${ }^{(9)}$. However, MRI alterations are not always correlated with the clinical picture ${ }^{(12)}$. Transfontanelle ultrasound, despite being more practical, has low sensitivity and specificity, and brain axial computed tomography is no more sensitive than the MRI ${ }^{(11)}$. Another important component of $\mathrm{BE}$ refers to the occurrence of auditory alterations ${ }^{(13,14)}$. In this patient, up until his discharge, it was not possible to perform the ABR test, which should be scheduled during the outpatient follow-up. Since the auditory apparatus is highly sensitive to bilirubin toxicity, this investigation is mandatory.

Medical practice varies considerably in the presence of neonatal hyperbilirubinemia among diverse institutions and among their different professionals ${ }^{(15)}$. National and international studies ${ }^{(15-16)}$ showed lack of consensus and preparedness of some maternity hospitals as to therapeutic orientation. A study conducted in some maternity hospitals of the city of Sao Paulo, in 2007, showed that two of them (8.6\% of those interviewed) stated they were unable to perform ET, in response to a questionnaire on management of neonatal jaundice ${ }^{(15)}$.

What is perceived is that when there is no uniformity in facilities as to proper management, there is a tendency to delay the use of more intensive therapy in full-term NB until the serum bilirubin level reaches values considerably higher than those used in the past to indicate ET. This practice, aligned with the tendency towards early hospital discharge, has led to a reappearance of kernicterus, as has been verified in the United States ${ }^{(8)}$.

In 1994, the American Academy of Pediatrics ${ }^{(8)}$ presented recommendations for the treatment of neonatal jaundice, updated in $2004^{(1)}$. In spite of this, the frequency of kernicterus has become more evident as population data undergo analysis. One study in Denmark reported that there were no described cases of kernicterus in the 20 years preceding 1994. From 1994 to 2002, eight cases were diagnosed (four of them due to $\mathrm{ABO}$ incompatibility) ${ }^{(17)}$.

An international study of medical records in patient files indicated that physicians (pediatricians and neonatologists) and nurses were not familiar with the clinical signs of $\mathrm{BE}$, as well as its progressive clinical manifestations ${ }^{(16)}$. 
On the other hand, Campistol et al. ${ }^{(18)}$ noted in seven patients with severe neonatal jaundice (two of them due to $\mathrm{Rh}$ incompatibility) lesions in the globus pallidus, verified by means of neuroimaging, besides neurological sequelae. They also reported there was an increment of observations of bilirubin-induced neurological dysfunction and they supposed that this disorder is related to the greater survival of extreme preterm NBs, to an increase in the immigrant population, and to better diagnoses by neuroimaging examinations, highlighting that it is still an objective of neonatology to prevent and diminish the effects of bilirubin toxicity ${ }^{(18)}$. Turkel et al. ${ }^{(19)}$, demonstrated in NBs with kernicterus consistent histological alterations in merely $10 \%$ of cases, and in the other cases, the lesion found was not specific (spongy degeneration and gliosis). These authors suggested that newborn brain cells with nonspecific lesions might have suffered another type of aggression, prior to the deposit of bilirubin, which could have occurred even at levels of hyperbilirubinemia close to those considered physiological.

In the present case, the diagnosis of kernicterus was based on maternal past history of RH factor incompatibility, clinical and laboratory data related to hematological tests, pending on definitive confirmation with audiology exams. These events, however, are noteworthy.

The current decrease in frequency of $\mathrm{Rh}$ factor hemolytic disease (over the last four years, for example, no Coombs-positive NB due to the Rh factor has been identified at our service at HGG) likely leads to the discredit or questioning of such an important illness. Associated with this is the lack of communication between prenatal and delivery services and the neonatal team; lack of attention to prenatal findings; lack of concern on the part of the neonatologist with the full-term icteric NB; and the lack of early follow-up after the baby was discharged. A combination of all these factors led to this outcome.

Effective prevention, with constant surveillance starting during the prenatal care, detection of patients at risk for hyperbilirubinemia, associated with an aggressive approach directed towards these NBs, eliminating the factors that transform bilirubin into a neurotoxin (hypoxemia, acidosis, dehydration, hypoglycemia, and infection) may avoid devastating sequelae. Bilirubin encephalopathy is totally preventable, thus, if a collective approach is adopted as a Public Health strategy, which clarifies maternal-infant care teams and family members, we will be providing an effective treatment of serious neonatal hyperbilirubinemia and therefore, avoiding, both $\mathrm{BE}$ and kernicterus.

\section{REFERENCES}

1. American Academy of Pediatrics. Subcommittee on hyperbilirubinemia in the newborn infant 35 or more weeks of gestation. Clinical practice guideline. Pediatrics. 2004;114(1):296-316.

2. Bhutani VK, Johnson LH. Newborn jaundice and kernicterus - health and societal perspectives. Indian J Pediatr. 2003;70(5):407-16.

3. Bhutani VK, Johnson LH, Jeffrey Maisels M, Newman TB, Phibbs C, Stark $A R$, et al. Kernicterus: epidemiological strategies for its prevention through systems-based approaches. J Perinatol. 2004;24(10):650-62.

4. Quintas C, Silva A. Icterícia neonatal. Consensos em Neonatologia. Sociedade Portuguesa de Pediatria. [cited 2011 Feb 12]. Available at: http://www.spp.pt/UserFiles/File/Consensos

5. Bhutani VK. Screening for severe neonatal hyperbilirubinemia. Pediatr Health. 2009;3(4):369-79.

6. Bhutani VK, Johnson L. Prevention of severe neonatal hyperbilirubinemia in healthy infants of 35 or more weeks of gestation: implementation of a systems based approach. J Pediatr (Rio J). 2007;83(2):289-93.

7. Segre AM, Bastos F. Icterícia neonatal. In: Segre CAM, Costa HPF, Lippi UG, editor. Perinatologia. Fundamentos e prática. 2a ed. São Paulo: Sarvier; 2009. p. 720-36.

8. Practice parameter: management of hyperbilirubinemia in the healthy term newborn. American Academy of Pediatrics. Provisional Committee for Quality Improvement and Subcommittee on Hyperbilirubinemia. Pediatrics.1994;94(4 Pt1):558-65.

9. Martich-Kriss V, Kollias SS, Ball WS Jr. MR findings in kernicterus. AJNR Am J Neuroradiol. 1995;16(4 Suppl):819-21.

10. Shahian M, Moslehi MA. Effect of albumin administration prior to exchange transfusion in term neonates with hyperbilirubinemia -- a randomized controlled trial. Indian Pediatr. 2010;47(3):241-4.

11. Yilmaz Y, Ekinci G. Thalamic involvement in a patient with kernicterus. Eur Radiol. 2002;12(7):1837-9.

12. Katar S, Akay HO, Taskesen M, Devecioglu C. Clinical and cranial magnetic resonance imaging (MRI) findings of 21 patients with serious hyperbilirubinemia. J Child Neurol. 2008;23(4):415-7.

13. Shapiro SM. Chronic bilirubin encephalopathy: diagnosis and outcome. Semin Fetal Neonatal Med. 2010;15(3):157-63.

14. Saluja S, Agarwal A, Kler N, Amin S. Auditory neuropathy spectrum disorder in late preterm and term infants with severe jaundice. Int $\mathrm{J}$ Pediatr Otorhinolaryngol. 2010;74(11):1292-7

15. Bastos F, Segre CAM, Brito JAA. Preliminary report on the management of neonatal jaundice in maternity clinics of São Paulo city, Brazil. einstein. 2007:5(1):56-62.

16. US Preventive Services Task Force. Screening of Infants for hyperbilirubinemia to prevent chronic bilirubin encephalopathy: US Preventive Services Task Force Recommendation Statement. Pediatrics. 2009;124(4);1172-7.

17. Bjerre JV, Ebbesen F. [Incidence of kernicterus in newborn infants in Denmark]. Ugeskr Laeger. 2006;168:686-91. Danish.

18. Campistol J, Galvez H, Cazorla AG, Málaga I, Iriondo M, Cusí V. Disfunción neurológica inducida por bilirrubina. Neurología. 2010. doi:10.1016/j. nrl.2010.03.013.

19. Turkel SB, Miller CA, Guttenberg ME, Moynes DR, Godgman JE. A clinical pathologic reappraisal of kernicterus. Pediatrics. 1982;69(3):267-74. 